\title{
Genetic Determination of the Antigenic Specificity of Flagellar Protein in Salmonella
}

\author{
By S. YAMAGUCHI AND T. IINO \\ The National Institute of Genetics, Misima, Japan
}

(Accepted for publication 27 August 1968)

\begin{abstract}
SUMMARY
Using non-flagellate $\left(f a^{-}\right)$mutants of gn-complex antigenic derivatives of a stable phase-I strain of Salmonella abortusequi, the positions of the antigenic specificity-determining sections on the genetic map of $H I$, a structural gene for flagellar protein, were located by establishing a system for selecting intra$H I$ recombinants. Before the recombination experiments, a factor analysis of the gn-complex antigens of the strains was made by cross-absorption tests: nine factors were detected.

P 22 phage-mediated transductions were carried out between different pairs of $H I$-linked $f l a$ mutants, whose $H I$-alleles were different and whose $f l^{-}$ sites were on opposite sides of $\mathrm{HI}$. The $\mathrm{fla}^{+}$transductants, present as swarms in semi-solid medium, were isolated and the composition of their flagellar antigens examined with specific antisera. Among I366 $\mathrm{fa}^{+}$transductants obtained, 26 clones were shown to have 'recombinant antigens' carrying some factors of one or both of the parental-type antigens. With several 'recombinant antigens', some new specificities with weak antigenicity were detected. The flagellar protein, 'flagellin', of an 'antigen recombinant' was proved to be a recombinant of the two parental flagellins by finger-printing analysis of tryptic digests.

On the assumption that these 'antigen recombinants' resulted from a single cross-over within $H I$, the relative positions of the antigenic specificitydetermining sections within donor and recipient $H I$ with regard to the crossover point were obtained for individual 'antigen recombinants'. Summarizing the relative positions thus inferred, it was shown that each of the antigenic specificity-determining sections maps as a unit; and that as a whole they form a linear array within $H I$. Sections specifying some tryptic peptides of flagellins were also mapped within $H \boldsymbol{I}$.
\end{abstract}

\section{INTRODUCTION}

Salmonella flagella exhibit a wide variety of antigenic specificities (Kauffmann, 1964). Many Salmonella species manifest two alternative types of flagellar antigen: one is called phase-r and the other phase-2 (Andrews, 1922). Genetical analysis by transduction shows that the phase-I and phase-2 specificities are determined by allelic genes at two loci, $\mathrm{HI}_{\mathrm{I}}$ and $\mathrm{Hz}_{2}$ (Lederberg \& Edwards, 1953). Chemically, a Salmonella flagellum is a polymer of a single protein, flagellin, the molecular weight of which is 36,000 to 40,000 (Kerridge, Horne \& Glauert, 1962; Asakura, Eguchi \& Iino, 1964; McDonough, 1965). The genes $\mathrm{HI}_{\mathrm{I}}$ and $\mathrm{Hz}_{2}$ are therefore the structural genes specifying the primary structures of the flagellins of the respective phases (Iino \& Lederberg, 1964).

Immunological tests show that the flagellar antigen is a complex composed of 
several antigenic factors. That is, one flagellin molecule carries several distinct antigenic determinants. The so-called gn-complex antigens, a group of phase-I antigens possessing the factor $\mathbf{g}$ in common, have been analysed antigenically in detail, as shown in the Kauffman-White scheme (Kauffmann, 1964). After reviewing the compositions of naturally occurring gn-complex antigens, lino (1959) proposed that the antigenic specificities are determined by several sections in the $H$ gene, each corresponding to a different antigenic specificity. According to this hypothesis, intragenic recombination between different alleles of $\mathrm{HI}$ or $\mathrm{H}_{2}$ will result in the production of a recombinant antigen carrying specificities derived from both parents, unless the specificity of each antigen is altered by conformational changes in the flagellin molecule resulting from recombination. Analysis of such recombinant antigens should therefore disclose the arrangement of antigen-determining sections within $H$ genes. Some evidences of intragenic recombination between the $\mathrm{H}_{2}$ alleles, $\mathrm{Hz}_{2}-\mathrm{I}, 2$ and $\mathrm{H}_{2}-e, n, x$ (lino, 1960), and between some mutant alleles of $\mathrm{HI}_{\mathrm{I}-\mathrm{i}}$ (Joys \& Stocker, 1963) has already been obtained, but the ordering of specificity-determining sections has not previously been attempted.

In the present study, an attempt has been made to map the antigenic specificitydetermining sections in $H_{I}$ by intragenic recombination between different alleles of $H I-g$. .

\section{METHODS}

Bacteria. Salmonella dublin NCTC4I97 (1,9,12; g,p:-), S. derby NCTC I729 (I, 4, 5, 12; g,f:-), and S. enteritidis NCTC4I96 (I,9,12; g,m:-) were received from Dr Joan Taylor (Central Public Health Laboratory, London). Salmonella sp. strain sJ6 (?; g,t:-) is a stock strain of this Institute. These naturally occurring strains are heterogeneous in various characters, for example, in their somatic antigens, phage sensitivity, etc. For the present study, four artificial strains were prepared by transferring the alleles of $H I-g$. . by $\mathrm{P}_{22}$ phage-mediated transduction from the above four naturally occurring strains to a single recipient strain $\operatorname{sJ} 24 \mathrm{I}(4, \mathrm{I2} ; \mathrm{a}:(\mathrm{e}, \mathrm{n}, \mathrm{x}))$, a phase-I stable strain of $S$. abortusequi. Their strain numbers and some characteristics are shown in Table $I$. The artificial strains are thought to have the same genetic background except $H r$ and its vicinity. Since they are stable in phase-I and have identical somatic antigens, only phase-I antigens are indicated here when describing their antigenic formulae. All of them are $\mathrm{nml}^{+}$.

Non-flagellate $\left(f a^{-}\right)$mutants were selected from strains TR6, TRI6 and TRI7 by phage M8, a mutant of phage $\chi$. This phage attacks motile Salmonella organisms except for some specific serotypes including gn-complex antigenic Salmonella, but cannot attack non-flagellate $\left(\mathrm{fla}^{-}\right)$or paralysed (mot) cells (Meynell, 196I). Phage M8 is a host-range mutant able to attack motile salmonellas with gn-complex antigens (Sasaki, 1962; Yamaguchi, 1968). The method used here for selecting $f^{-} a^{-}$mutants was that described by Joys \& Stocker (1965) for isolating fla $^{-}$mutants from $S$. typhiamurium LT2 with the $\chi$-phage. The $f l a^{-}$mutants used in the present study are listed in Table 2. They are stable and their mutation sites are very closely linked to $H \boldsymbol{r}$. Complementation tests with the mutants of the already known $f l a$ cistrons showed that TR I6-fla-227 and TR I 7-fla-25I carry deletions in the fla $A$ cistron and that TR6-fla-373 has a deletion extending over the $f a A, B$, and $D$ cistrons. The other three mutants, TR6-fla-35I, TRI6-fla-204, and TRI7-fla-263, do not complement each other but com- 
plement with every $f a^{-}$mutant of the known $f a$ cistrons. The possibly new cistron represented by these three mutants is tentatively described as $f a L$ in this paper. Reciprocal transductions were made between each of these mutants and a $\mathrm{fl}^{-}$mutant of SJ24I ( $\mathrm{FlaA}^{-} \mathrm{HI}_{\mathrm{I}} a$ ), and the flagellar antigen types of the $\mathrm{fla}^{+}$transductants examined. From the ratios of the transductants carrying the donor-type antigen to those carrying the recipient-type antigen in every cross, it was shown that the fla A cistron and the $f a L$ cistron are on the opposite sides of $H I$. Details of the mapping of these $f a^{-}$sites will be published elsewhere.

Table I. Derivatives of Salmonella abortusequi SJ24I, given HI-g...-alleles from gn-complex antigenic Salmonella by transduction

\begin{tabular}{|c|c|c|c|c|c|c|c|}
\hline \multirow{2}{*}{$\begin{array}{c}\text { Strain } \\
\text { no. }\end{array}$} & \multirow[b]{2}{*}{$O$ antigens } & \multicolumn{2}{|c|}{$\mathbf{H}$ antigens } & \multicolumn{2}{|c|}{$\begin{array}{l}\text { Sensitivity } \\
\text { to phage }\end{array}$} & \multirow[b]{2}{*}{$n m l^{*}$} & \multirow[b]{2}{*}{ Donor of $H l-g . .}$. \\
\hline & & phase I & phase 2 & $\mathbf{P}_{22}$ & M8 & & \\
\hline $\begin{array}{l}\text { TR6 } \\
\text { TRII }\end{array}$ & $\begin{array}{l}4,12 \\
4,12\end{array}$ & $\begin{array}{l}\text { g,t } \\
\text { g,p }\end{array}$ & $\begin{array}{l}(\mathrm{e}, \mathrm{n}, \mathbf{x}) \dagger \\
(\mathrm{e}, \mathrm{n}, \mathbf{x})\end{array}$ & $\begin{array}{l}s \ddagger \\
\text { s }\end{array}$ & $\begin{array}{l}\mathbf{s} \\
\mathbf{s}\end{array}$ & $\begin{array}{l}+ \\
+\end{array}$ & $\begin{array}{l}\text { Salmonella sp. sJ6 } \\
\text { S. dublin NCTC4197 }\end{array}$ \\
\hline TRI6 & 4,12 & f,g & $(e, n, x)$ & $\mathbf{s}$ & $\mathbf{s}$ & + & S. derby NCTC1 729 \\
\hline TR17 & 4,12 & g,m & $(e, n, x)$ & $\mathbf{s}$ & $\mathbf{s}$ & + & S. enteritidis NCTC4196 \\
\hline
\end{tabular}

* The $n m l$ character was determined by the presence or absence of $\epsilon-N$-methyllysine in acidhydrolysed flagellin examined in the Hitachi automatic amino acid analyser.

to: unexpressed antigen type.

$\ddagger$ s: 'sensitive' to the indicated phage.

\section{Table 2. Properties of non-flagellate mutants of Salmonella}

Frequency of co-transduction with $\mathrm{Hr}$ : percentage of $\mathrm{fla}^{+}$clones with the phase-I antigen of donor in the total $\mathrm{fla}^{+}$transductants produced in the P22 phage-mediated transduction from Salmonella abortusequi sJ24I (a: $(\mathrm{e}, \mathrm{n}, \mathrm{x}))$ to the $\mathrm{fla}^{-}$mutant. About $500 \mathrm{fla}^{+}$transductants were examined for each strain.

Complementation group: examined by trail formation in the P22 phage-mediated transduction from the $f a^{-}$mutant to standard mutants of the known $f a$ cistrons derived from S. typhimurium TM2 (Iino \& Enomoto, 1966). The sequence of the fla cistrons is his... flaBflaD-flaA-Hr-faL...motA,B...trp.

\begin{tabular}{lcccc}
\multicolumn{1}{c}{ Strain } & Reversion & $\begin{array}{c}\text { Frequency of } \\
\text { co-transduction } \\
\text { with } H I(\%)\end{array}$ & $\begin{array}{c}\text { Complementation } \\
\text { group }\end{array}$ & Original strain \\
TR6-fla-35I & - & 89 & L & TR6 \\
TR6-fla-373 & - & 87 & A, B, D & TR6 \\
TRI6-fla-204 & - & 96 & L & TR16 \\
TRI6-fla-227 & - & 88 & A & TRI6 \\
TRI7-fla-25I & - & 54 & A & TRI7 \\
TRI7-fla-263 & - & 90 & L & TRI7
\end{tabular}

Media. Nutrient broth was composed of $\mathrm{I} \%(\mathrm{w} / \mathrm{v})$ peptone and $\mathrm{I} \%(\mathrm{w} / \mathrm{v})$ meat extract, adjusted to $\mathbf{p H} 7 \cdot 2$. Nutrient agar was prepared by the addition of $1 \cdot 5 \%$ (w/v) agar to nutrient broth. Semi-solid medium (Edwards \& Bruner, 1942; Stocker, Zinder \& Lederberg, 1953) was prepared by adding $0.35 \%(w / v)$ agar and $8 \%(w / v)$ gelatin to the nutrient broth. All cultures were incubated at $37^{\circ}$.

Immunization procedure. Since the content of flagellar antigen of a bacterium is roughly proportional to its motility, the bacteria used for immunization, agglutination or absorption were first passed through semi-solid medium. Overnight broth cultures inoculated with highly motile organisms were centrifuged and the pellet suspended in 
formalinized saline (formaldehyde concentration: $0.5 \%$ ) to a final concentration of about $5 \times 10^{8}$ bacteria/ml. Rabbits were immunized by one intraperitoneal and five successive intravenous injections of a total of $6 \mathrm{ml}$. of bacterial suspension at 3-day intervals, and bled I week after the final injection. The antisera were processed according to Edwards \& Ewing (1955).

Absorption of antisera. Highly motile organisms of an absorbing strain were grown in nutrient broth overnight, and used to inoculate trays $(20 \times 30 \times \mathrm{I} \cdot 8 \mathrm{~cm}$.) each containing $200 \mathrm{ml}$. nutrient agar. After incubation for $24 \mathrm{hr}$, the bacteria were harvested in formalinized saline (formaldehyde concentration: $0.5 \%$ ), and the suspension kept at room temperature overnight. The bacteria were then centrifuged, resuspended in sterile saline and kept at $0^{\circ}$. This suspension was centrifuged before use and the pellet mixed with the antiserum to be absorbed in the proportion of about $0.5 \mathrm{~g}$. wet weight organisms to $\mathrm{I} \cdot \mathrm{O} \mathrm{ml}$. serum. After $2 \mathrm{hr}$ at $37^{\circ}$ the mixture was centrifuged. If this onceabsorbed serum still agglutinated the absorbing organisms, this process was repeated until no activity with the absorbing organisms remained.

Titration of antisera. The titres of antisera were determined by tube agglutination of two-fold serial dilutions incubated at $52^{\circ}$ for $2 \mathrm{hr}$ and expressed as the reciprocal or its logarithm (to base 2) of the highest dilution showing activity.

Transduction between fla $^{-}$mutants. Phage P 22 (Zinder \& Lederberg, 1952) was used as transducing phage throughout. The phage was propagated by the soft agar-layer method (Adams, 1959) on a donor strain, and the lysate mixed with broth culture of the recipient (about $5 \times 10^{8} \mathrm{cells} / \mathrm{ml}$.) at a m.o.i. of 5 to 10 . After $10 \mathrm{~min}$. at $37^{\circ}$, the mixture was diluted $10^{-1}$ and $10^{-2}$ with nutrient broth, and the dilutions brushed in line on semi-solid medium. The $\mathrm{fla}^{+}$transductants were selected as swarms after incubation for $15 \mathrm{hr}$.

Preparation of flagellin. Broth cultures of highly motile bacteria were inoculated on nutrient agar in trays. After incubation for $24 \mathrm{hr}$ at $37^{\circ}$, the bacteria were harvested in saline, washed, resuspended in distilled water, and de-flagellated by shaking (about 750 strokes/min., $25 \mathrm{~mm}$. amplitude). The suspension was centrifuged at $3000 \mathrm{rev}$./ $\mathrm{min}$. for $40 \mathrm{~min}$. The supernatant, containing the flagella, was then centrifuged at $30,000 \mathrm{rev} . / \mathrm{min}$. in a Spinco Model L ultracentrifuge for $45 \mathrm{~min}$. The deposited flagella were disintegrated into monomers of flagellin by treatment with $0.0 \mathrm{I} \mathrm{N}-\mathrm{HCl}$ for $30 \mathrm{~min}$. at room temperature. The solution was then centrifuged at 30,000 rev./min. for $45 \mathrm{~min}$. to remove turbidity, and the supernatant dialysed for $5 \mathrm{hr}$ against three changes of distilled water and lyophilized in vacuo. No further preparation was undertaken since the flagellin preparation thus obtained showed only one peak and one band in column chromatography using DEAE-cellulose and electrophoresis, respectively (Enomoto \& Iino, 1962).

Tryptic peptide maps. Lyophilized flagellin was dissolved in $0.05 \mathrm{M}$-phosphate buffer (pH 8.0) at $2 \%$, denaturated by heating at $90^{\circ}$ for $5 \mathrm{~min}$., and digested with trypsin $(2 \%)$ at $25^{\circ}$ for $24 \mathrm{hr}$. A sample of the digest was applied to a sheet $(40 \times 30 \mathrm{~cm}$.) of Tôyō no. 50 filter paper and subjected to electrophoresis in pyridine + acetic acid+ water ( $135+\mathrm{I} 5+\mathrm{I}$ by vol.) at $\mathrm{pH} 6.65$ for $3.5 \mathrm{hr}$ at $15 \mathrm{~V} / \mathrm{cm}$. After drying, the paper was subjected twice to ascending chromatography with $n$-butyl alcohol + acetic acid + water $(3+I+I$ by vol.) and the peptide spots developed with ninhydrin dissolved in acetone $(0.25 \%, \mathrm{w} / \mathrm{v})$. 


\section{RESULTS}

Further analysis of factor compositions of gn-complex antigens

Although the compositions of the gn-complex antigens have been analysed in some detail, it has often been recognized that the factor $g$ may be further subdivided into several factors (e.g. Edwards \& Ewing, 1955). Thus, an analysis of the gn-complex antigens was carried out with the four gn-complex antigenic strains, TR6 $(g, t)$, TRI I $(\mathrm{g}, \mathrm{p}), \operatorname{TRI} 6(\mathrm{f}, \mathrm{g}), \operatorname{TRI} 7(\mathrm{~g}, \mathrm{~m})$, by cross-absorption.

Table 3. Cross-absorption-agglutination test of anti-gn-sera

\begin{tabular}{|c|c|c|c|c|c|}
\hline \multirow[b]{2}{*}{ Antiserum } & \multirow[b]{2}{*}{ Absorbed with } & \multicolumn{4}{|c|}{ Activity of absorbed antiserum on } \\
\hline & & TR6 & TRII & TRI6 & TRI7 \\
\hline \multirow[t]{6}{*}{ Anti-TR6 } & TRII & + & - & + & + \\
\hline & TRI6 & + & + & - & + \\
\hline & TRI7 & + & - & + & - \\
\hline & TRII and TRI 6 & + & - & - & + \\
\hline & TRII and TRI7 & + & - & + & - \\
\hline & TRI 6 and TRI7 & + & - & - & - \\
\hline \multirow[t]{6}{*}{ Anti-TR I I } & TR6 & - & + & + & + \\
\hline & TRI6 & + & + & - & + \\
\hline & TRI7 & - & + & - & - \\
\hline & TR6 and TRI6 & - & + & - & + \\
\hline & TR6 and TRI7 & - & + & - & - \\
\hline & TRI 6 and TRI7 & - & + & - & - \\
\hline \multirow[t]{6}{*}{ Anti-TRI6 } & TR6 & - & + & + & + \\
\hline & TRII & + & - & + & - \\
\hline & TRI7 & + & - & + & - \\
\hline & TR6 and TRI I & - & - & + & - \\
\hline & TR6 and TRI 7 & - & - & + & - \\
\hline & TRII and TRI7 & + & - & + & - \\
\hline \multirow[t]{6}{*}{ Anti-TR I 7} & TR6 & - & + & + & + \\
\hline & TRII & + & - & - & + \\
\hline & TRI6 & + & + & - & + \\
\hline & TR6 and TRI I & - & - & - & + \\
\hline & TR6 and TRI6 & - & + & - & + \\
\hline & TRII and TRI 6 & + & - & - & + \\
\hline
\end{tabular}

Several rabbits were immunized with TR6, TRII, TRI6 and TRI7, respectively. Antisera of titre of 12,800 to 25,600 against the homologous antigens were obtained. These were fully absorbed with organisms of one or two non-homologous test strains, and the residual cross-reactivities examined by slide agglutination (Table 3 ). Since the somatic (o) antigens are common to all the strains used, the activities remaining after absorption are those for the factor(s) present on the flagellar antigen of the immunizing strain but absent from that of the absorbing strain. The results indicated the presence of at least nine factors in the gn-complex antigens examined. Four were specific to the respective strains and were therefore regarded, respectively, as factors $t, p, f$, and $m$ in the Kauffmann-White scheme. The other five factors common to two or three strains were regarded as parts of a complex of factors, which has so far been given the symbol $g$; they will be described as $g_{1}, g_{2}, g_{3}, g_{4}$ and $g_{5}$, respectively. The factor 
compositions of the four strains are shown in Table 4. There remained the possibility that besides these nine factors a factor or factors common to all the four antigens exists, which would have been overlooked in the present cross-absorption test.

\section{Table 4. Factors present in the gn-complex antigens}

$\left(g_{0}\right)$ : a factor or a complex of factors common to all these gn-complex antigens which would not be detected in the present cross-absorption test.

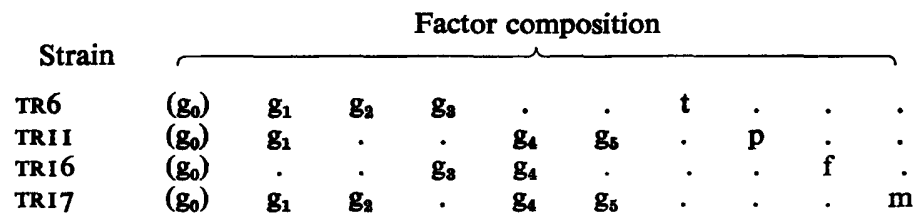

Table 5. Anti-factor sera used for detecting the factors of flagellar antigens of $\mathrm{fla}^{+}$recombinants from different pairs of $\mathrm{fla}^{-}$mutants

\begin{tabular}{|c|c|c|c|}
\hline \multirow{2}{*}{$\begin{array}{l}\text { Factor to be } \\
\text { detected }\end{array}$} & \multirow[b]{2}{*}{ Anti-factor(s) serum used } & \multicolumn{2}{|c|}{$\begin{array}{l}\text { Preparation of the anti- } \\
\text { factor(s) serum }\end{array}$} \\
\hline & & Serum & Absorbed with \\
\hline \multicolumn{4}{|c|}{ (a) For $\mathrm{fla}^{+}$transductants between $\mathrm{fla}^{-}$mutants of TR6 and TRI 6} \\
\hline $\begin{array}{l}\mathrm{g}_{1} \\
\mathrm{~g}_{2} \\
\mathrm{~g}_{4} \\
\mathrm{t} \\
\mathrm{f}\end{array}$ & $\begin{array}{l}\text { Anti-g } g_{1}, g_{5}, p \\
\text { Anti-g } g_{2}, \mathrm{~m} \\
\text { Anti- } g_{4}, g_{5}, p \\
\text { Anti-t } \\
\text { Anti-f }\end{array}$ & $\begin{array}{l}\text { Anti-TR I I } \\
\text { Anti-TR I } 7 \\
\text { Anti-TR I I } \\
\text { Anti-TR6 } \\
\text { Anti-TR I } 6\end{array}$ & $\begin{array}{l}\text { TRI6 } \\
\text { TRII } \\
\text { TR6 } \\
\text { TRI6 and TRI7 } \\
\text { TR6 and TRII }\end{array}$ \\
\hline \multicolumn{4}{|c|}{ (b) For $\mathrm{fla}^{+}$transductants between $\mathrm{fla}^{-}$mutants of TR6 and TRI7 } \\
\hline $\begin{array}{l}\mathbf{g}_{8} \\
\mathbf{g}_{4} \\
\mathbf{g}_{5} \\
\mathbf{t} \\
\mathrm{m}\end{array}$ & $\begin{array}{l}\text { Anti-g } g_{8}, f \\
\text { Anti-g } g_{4}, f \\
\text { Anti-g } g_{5}, p \\
\text { Anti-t } \\
\text { Anti-m }\end{array}$ & $\begin{array}{l}\text { Anti-TR I6 } \\
\text { Anti-TRI6 } \\
\text { Anti-TRI I } \\
\text { Anti-TR6 } \\
\text { Anti-TR17 }\end{array}$ & $\begin{array}{l}\text { TRI7 } \\
\text { TR6 } \\
\text { TR6 and TR I } 6 \\
\text { TRI } 6 \text { and TRI7 } \\
\text { TR6 and TRII }\end{array}$ \\
\hline \multicolumn{4}{|c|}{ (c) For $\mathrm{fla}^{+}$transductants between $\mathrm{fla}^{-}$mutants of TRI6 and TRI7 } \\
\hline $\mathbf{g}_{1}$ & $\begin{array}{l}\text { Anti-g } g_{1}, g_{6}, p \\
\text { Or anti-g } g_{1}, g_{2}, t\end{array}$ & $\begin{array}{l}\text { Anti-TR I I } \\
\text { Anti-TR6 }\end{array}$ & $\begin{array}{l}\text { TRI } 6 \\
\text { TRI6 }\end{array}$ \\
\hline $\mathbf{g}_{\mathbf{2}}$ & Anti-g, $g_{2}, t$ & Anti-TR6 & TRII and TRI 6 \\
\hline $\mathbf{g}_{3}$ & Anti-gs,t & Anti-TR6 & TRI7 \\
\hline $\mathrm{g}_{5}$ & Anti-g $g_{5}, p$ & Anti-TR I I & TR6 and TRI 6 \\
\hline f & Anti-f & Anti-TR I 6 & TR6 and TRI7 \\
\hline m & Anti-m & Anti-TR 17 & TR6 and TRI I \\
\hline
\end{tabular}

Recombination within $\mathrm{HI}$

The system for detecting recombinants was as follows. P22 phage-mediated transduction was done between a pair of non-flagellate ( $\left.f a^{-}\right)$mutants whose $\mathrm{HI}$-alleles differed; whose $\mathrm{fla}^{-}$sites were cotransduced with $\mathrm{HI}$ in high frequency; and were on

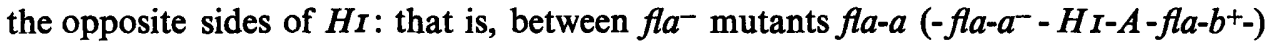
and $f l a-b\left(-f l a-a^{+}-H I-B-f l a-b^{-}-\right)$. The $f l a^{+}$transductants developing as swarms in semisolid medium were isolated and their antigenic compositions examined. The occurrence of an $\mathrm{fla}^{+}$transductant in this case required at least one cross-over in the region between the two $f a^{-}$sites surrounding $H I$. Thus, the closer the $f l a^{-}$sites to $H I$, the larger should be the relative frequency of intra-HI recombinants among the $\mathrm{fla}^{+}$transductants. 
Table 6. Factors present in the flagellar antigens of $\mathrm{fla}^{+}$recombinants from different pairs of $\mathrm{fla}^{-}$mutants

Factor composition of flagellar antigen: examined by slide agglutination with anti-factor sera listed in Table 5 .

$\mathrm{A}, \mathrm{B}, \mathrm{D}$ and $\mathrm{L}$ in parentheses: complementation groups of $f a^{-}$mutants.

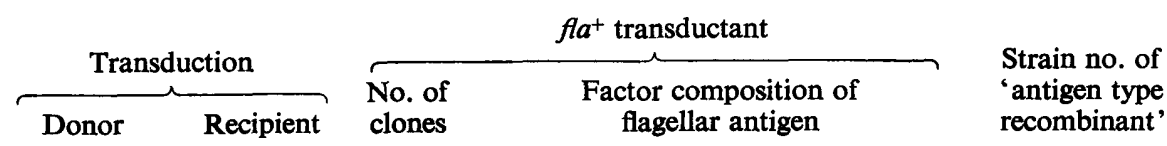

(a) The $f a^{+}$transductants between TR6- and TRI6- $f a^{-}$mutants

\begin{tabular}{|c|c|c|c|c|c|c|c|c|c|}
\hline & & & $\mathbf{g}_{1}$ & $\mathbf{g}_{2}$ & $\mathbf{g}_{\mathbf{4}}$ & $\mathrm{f}$ & $\mathbf{t}$ & & \\
\hline $\begin{array}{r}\text { TR6-fla-373 } \\
(\mathrm{A}, \mathrm{B}, \mathrm{D})\end{array}$ & $\begin{array}{l}\text { TRI6-fla-204 } \\
\text { (L) }\end{array}$ & $\begin{array}{r}63 \\
32 \\
3 \\
1\end{array}$ & $\begin{array}{l}+ \\
- \\
-\end{array}$ & $\begin{array}{l}+ \\
- \\
-\end{array}$ & $\begin{array}{l}- \\
+ \\
+ \\
-\end{array}$ & $\begin{array}{l}- \\
+ \\
-\end{array}$ & $\begin{array}{l}+ \\
- \\
+ \\
+\end{array}$ & $\begin{array}{l}\text { (TR6-type) } \\
\text { (TRI6-type) } \\
\text { (Rec.-type I) } \\
\text { (Rec.-type II) }\end{array}$ & $\begin{array}{l}\text { SJI } 740 \text { to sJI742 } \\
\text { SJI } 743\end{array}$ \\
\hline $\begin{array}{l}\text { TRI6-fla-204 } \\
\text { (L) }\end{array}$ & $\begin{array}{c}\text { TR6-fla-373 } \\
(\mathbf{A}, \mathbf{B}, \mathbf{D})\end{array}$ & $\begin{array}{l}85 \\
15\end{array}$ & + & + & $\overline{+}$ & $\overline{+}$ & + & $\begin{array}{l}\text { (TR6-type) } \\
\text { (TRI6-type) }\end{array}$ & $\dot{\bullet}$ \\
\hline $\begin{array}{l}\text { TR6-fla-35I } \\
\text { (L) }\end{array}$ & $\begin{array}{l}\text { TRI6-fla-227 } \\
\text { (A) }\end{array}$ & $\begin{array}{r}28 \\
68 \\
3\end{array}$ & $\begin{array}{l}+ \\
+\end{array}$ & $\begin{array}{l}+ \\
+\end{array}$ & $\begin{array}{l}- \\
+ \\
+\end{array}$ & $\begin{array}{l}- \\
+ \\
+\end{array}$ & $\begin{array}{l}+ \\
- \\
-\end{array}$ & $\begin{array}{l}\text { (TR6-type) } \\
\text { (TRI6-type) } \\
\text { (Rec.-type III) }\end{array}$ & sJi744 to sJi746 \\
\hline $\begin{array}{l}\text { TRI6-fla-227 } \\
\text { (A) }\end{array}$ & $\begin{array}{l}\text { TR6-fla-35I } \\
\text { (L) }\end{array}$ & $\begin{array}{r}35 \\
64 \\
I\end{array}$ & $\begin{array}{l}+ \\
- \\
-\end{array}$ & $\frac{+}{+}$ & $\begin{array}{l}- \\
+ \\
+\end{array}$ & $\begin{array}{l}- \\
+ \\
+\end{array}$ & $\begin{array}{l}+ \\
- \\
-\end{array}$ & $\begin{array}{l}\text { (TR6-type) } \\
\text { (TRI6-type) } \\
\text { (Rec.-type IV) }\end{array}$ & SJI $747 \stackrel{.}{.}$ \\
\hline
\end{tabular}

(b) The $\mathrm{fla}^{+}$transductants between TR6- and TRI 7-fla- mutants

\begin{tabular}{|c|c|c|c|c|c|c|c|c|c|}
\hline & & & $\mathbf{g}_{3}$ & $\mathbf{g}_{4}$ & $\mathbf{g}_{5}$ & $\mathrm{~m}$ & $\mathbf{t}$ & & \\
\hline $\begin{array}{c}\text { TR6-fla-373 } \\
(\mathbf{A}, \mathbf{B}, \mathbf{D})\end{array}$ & $\begin{array}{l}\text { TRI7-fla-263 } \\
\text { (L) }\end{array}$ & $\begin{array}{l}56 \\
44\end{array}$ & + & $\bar{t}$ & $\overline{+}$ & $\overline{+}$ & $\begin{array}{l}+ \\
-\end{array}$ & $\begin{array}{l}\text { (TR6-type) } \\
\text { (TRI7-type) }\end{array}$ & \\
\hline $\begin{array}{l}\text { TRI I- } \text { fla }^{-26} 6_{3} \\
\text { (L) }\end{array}$ & $\begin{array}{c}\text { TR6-fla-373 } \\
(\mathbf{A}, \mathbf{B}, \mathrm{D})\end{array}$ & $\begin{array}{l}88 \\
52\end{array}$ & $\begin{array}{l}+ \\
-\end{array}$ & $\bar{t}$ & $\bar{t}$ & $\bar{t}$ & + & $\begin{array}{l}\text { (TR6-type) } \\
\text { (TRI7-type) }\end{array}$ & \\
\hline $\begin{array}{l}\text { TR6-fla-35I } \\
\text { (L) }\end{array}$ & $\begin{array}{l}\text { TRI7-fla-25I } \\
\text { (A) }\end{array}$ & $\begin{array}{l}17 \\
91\end{array}$ & + & $\bar{t}$ & $\overline{+}$ & $\bar{t}$ & + & $\begin{array}{l}\text { (TR6-type) } \\
\text { (TRI7-type) }\end{array}$ & \\
\hline $\begin{array}{l}\text { TRI 7-fla-25I } \\
\text { (A) }\end{array}$ & $\begin{array}{l}\text { TR6-fla-35I } \\
\text { (L) }\end{array}$ & $\begin{array}{r}23 \\
98 \\
1\end{array}$ & $\begin{array}{l}+ \\
- \\
-\end{array}$ & $\begin{array}{l}- \\
+\end{array}$ & $\begin{array}{l}- \\
+ \\
+\end{array}$ & $\begin{array}{l}- \\
+ \\
+\end{array}$ & $\begin{array}{l}+ \\
+\end{array}$ & $\begin{array}{l}\text { (TR6-type) } \\
\text { (TRI7-type) } \\
\text { (Rec.-type V) }\end{array}$ & SJI 748 \\
\hline
\end{tabular}

(c) The $\mathrm{fla}^{+}$transductants between TRI6- and TRI7- $f a^{-}$mutants

\begin{tabular}{|c|c|c|c|c|c|c|c|c|c|c|}
\hline & & & & & & & \\
\hline & & & $\mathbf{g}_{1}$ & $\mathbf{g}_{2}$ & $\mathbf{g}_{\mathbf{a}}$ & $\mathbf{g}_{5}$ & f & $\mathrm{m}$ & & \\
\hline \multirow{3}{*}{$\begin{array}{l}\text { TRI6-fla-227 } \\
\text { (A) }\end{array}$} & \multirow{3}{*}{$\begin{array}{l}\text { TRI7-fla-263 } \\
\text { (L) }\end{array}$} & 74 & - & - & + & - & + & - & (TRI6-type) & - \\
\hline & & 56 & & + & - & + & - & + & (TRI7-type) & - \\
\hline & & 7 & + & + & + & - & + & - & (Rec.-type VI) & $\begin{array}{l}\text { SJI } 749 \text { to } \\
\text { SJI } 755\end{array}$ \\
\hline \multirow{4}{*}{$\begin{array}{l}\text { TRI } 7-f l a-263 \\
\text { (L) }\end{array}$} & \multirow{4}{*}{$\begin{array}{l}\text { TRI6-fla-227 } \\
\text { (A) }\end{array}$} & 92 & - & - & + & - & + & - & (TR I6-type) & . \\
\hline & & 35 & & + & - & + & - & + & (TRI7-type) & \\
\hline & & 5 & + & + & + & - & + & - & (Rec.-type VII) & $\begin{array}{l}\text { SJI756 to } \\
\text { SJI760 }\end{array}$ \\
\hline & & I & - & + & + & - & + & - & (Rec.-type VIII) & $\operatorname{sj1} 761$ \\
\hline \multirow{3}{*}{$\begin{array}{l}\text { TRI6-fla-204 } \\
\text { (L) }\end{array}$} & \multirow{3}{*}{$\begin{array}{l}\text { TRI 7-fla-25I } \\
\text { (A) }\end{array}$} & II & - & - & + & - & + & - & (TRI6-type) & . \\
\hline & & $7 I$ & & + & - & + & - & + & (TRI7-type) & \\
\hline & & 2 & - & - & - & + & - & + & (Rec.-type IX) & $\begin{array}{l}\text { sJI } 762 \text { and } \\
\text { sJI } 763\end{array}$ \\
\hline \multirow{4}{*}{$\begin{array}{l}\text { TRI7-fla-25I } \\
\text { (A) }\end{array}$} & \multirow{4}{*}{$\begin{array}{l}\text { TRI6-fla-204 } \\
\text { (L) }\end{array}$} & 22 & - & - & + & - & + & - & (TRI6-type) & . \\
\hline & & 120 & & + & - & + & - & + & (TRI7-type) & \\
\hline & & $\mathbf{I}$ & - & - & - & + & - & + & (Rec.-type X) & SJI 764 \\
\hline & & I & + & - & - & + & - & + & (Rec-type XI) & sil 765 \\
\hline
\end{tabular}


Transductions were made in the combinations mentioned above, using two $\mathrm{Hr}$ linked $\mathrm{fla}^{-}$mutants each of TR6, TRI6 and TRI7, listed in Table 2; the $\mathrm{fla}^{-}$sites of the two were on the opposite sides of $H I$. The antigenic compositions of the $f a^{+}$transductants obtained were examined by slide agglutination tests with anti-factor(s) sera (Table 5). Since not all the antisera for single factors were available, antisera for a complex of factors were sometimes used. For example, anti- $\mathrm{g}_{1}, \mathrm{~g}_{5}, \mathrm{p}$ serum was used to detect factor $\mathrm{g}_{1}$ of the transductants formed in the cross between $\mathrm{fl}^{-}$mutants of TR6 $\left(g_{1}, g_{2}, g_{3}, t\right)$ and TRI6 $\left(g_{3}, g_{4}, f\right)$, because factors $g_{5}$ and $p$ were absent from both of the parental type antigens. As another example, anti- $g_{1}, g_{5}, p$ and anti- $g_{1}, g_{2}, t$ sera were used to detect factor $\mathrm{g}_{1}$ of transductants obtained from crosses between $\mathrm{fla}^{-}$ mutants of TRI6 $\left(\mathrm{g}_{3}, \mathrm{~g}_{4}, \mathrm{f}\right)$ and TRI7 $\left(\mathrm{g}_{1}, \mathrm{~g}_{2}, \mathrm{~g}_{4}, \mathrm{~g}_{5}, \mathrm{~m}\right)$. The former was used for the detection of $g_{1}$ in clones lacking factor $g_{5}$, and the latter for $g_{1}$ in those lacking factor $\mathrm{g}_{2}$.

The majority ( 1340 clones) of the total $1366 \mathrm{fla}^{+}$transductants had either donoror recipient-type antigens, while the remaining 26 had new combinations of antigens (Table 6). For example, four types of transductant clones were obtained in transducing from TR6-fla-373 $\left(H I-g_{1}, g_{2}, g_{3} t\right)$ to TRI6-fla-204 $\left(H I-g_{3}, g_{4}, f\right)$ as shown in Table $6(a)$. Among them, the first and second were the donor- and the recipient-types, respectively, and the remaining two were new types; the one carried factor $t$ of the donor together with $\mathbf{g}_{4}$ of the recipient, and the other carried only $\mathrm{t}$ of the donor, among the factors tested. All in all, eleven such new types (recombinant-type I to XI in Table 6) were found in the present experiment. Among them, seven types had some factors of both of the donor- and the recipient-type antigens, and the other four had only part of the factors of one of the parental type antigen. On the supposition that these new type clones arose by intragenic recombination between alleles of $\mathrm{HI}-\mathrm{g}$..., they were designated as 'antigen recombinants', and the new type antigens as 'recombinant antigens.'

\section{Serological nature of 'recombinant antigens'}

One strain of each of the eleven types of recombinant was examined for the antigenic reactivity of their individual factors and also for the existence of antigenic factors absent from the parental type antigens. Individual factors were examined by measuring the titres of anti-factor(s) sera with organisms of the test strains. These sera were those used to detect 'antigen recombinants' (Table 5). As shown in Table 7, the reactivity of individual factors of the 'recombinant antigens' was almost equal to that of the corresponding factors of the parental type antigens.

A rabbit was immunized with actively motile cells of each 'antigen recombinant' to be tested. This antiserum was then repeatedly absorbed with a mixture of the parental strains. Since the 'antigen recombinants' used as immunogens had been lysogenized with $P_{22}$ phage, which is known to cause formation of somatic antigen I by the host organism (Zinder, 1957), the absorbing bacteria were first lysogenized with the phage. After every absorption, residual activity was titrated with the homologous antigen by tube agglutination (Table 8). Antisera, except those against SJI740, SJI 747 and SJI749, were easily inactivated by several absorptions; that is, there was no factor on these 'recombinant antigens' other than those present on the parental type antigens. Weak activities remained against SJI 740, SJI 747 and SJI 749 after full absorption. These fully absorbed antisera did not agglutinate any antigen used here other than their respective 
homologous antigens. Also they did not agglutinate salmonellas with the following

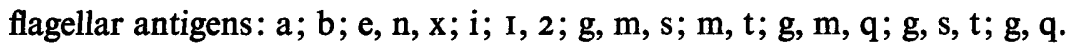

Although some 'recombinant antigens' had a unique antigenic pattern, the results obtained here indicate that of the 'recombinant antigens', at least seven types were almost complete mosaics, made up partly of donor-type antigen and partly of recipienttype antigen. The other six types may also be regarded as molecular mosaics, assuming that an active part of the antigen of one parent antigen had been replaced by an inactive part from the other parent.

Table 7. Antigenic reactivity of individual factors of the flagellar antigens in the 'antigen recombinants'

Titres of the anti-factor(s) antisera on the indicated antigens were determined by tube agglutination and expressed as log to base 2 .

Log titre to base 2 of anti-factor(s) serum

Antigen

(Factor to be examined)

(a) 'Antigen type recombinants' between TR6- and TRI6-fla' mutants

\begin{tabular}{|c|c|c|c|c|c|}
\hline & $\begin{array}{c}\text { Anti-g } g_{1}, g_{5}, p \\
\left(g_{1}\right)\end{array}$ & $\begin{array}{l}\text { Anti-g } g_{2}, \mathrm{~m} \\
\left(\mathrm{~g}_{2}\right)\end{array}$ & $\begin{array}{c}\text { Anti-g } g_{4}, g_{5}, p \\
\left(g_{4}\right)\end{array}$ & $\begin{array}{l}\text { Anti-f } \\
\text { (f) }\end{array}$ & $\underset{(t)}{\text { Anti-t }}$ \\
\hline $\left.\begin{array}{l}\text { TR6 } \\
\text { TRI6 }\end{array}\right\}$ (Parental type) & $\left\{\begin{array}{l}5 \\
<0\end{array}\right.$ & $\begin{array}{r}7 \\
<0\end{array}$ & $\begin{array}{r}<0 \\
9\end{array}$ & $\begin{array}{r}<0 \\
9\end{array}$ & $\begin{array}{r}\text { II } \\
<0\end{array}$ \\
\hline sJ1740 (Rec.-type I) & $<0$ & $<0$ & 7 & $<0$ & II \\
\hline sJI743 (Rec.-type II) & $<0$ & $<0$ & $<0$ & $<0$ & I I \\
\hline sJ1744 (Rec.-type III) & 5 & 7 & 8 & 9 & $<0$ \\
\hline sJI747 (Rec.-type IV) & $<0$ & 7 & 9 & 8 & $<0$ \\
\hline
\end{tabular}

(b) 'Antigen type recombinants' between TR6- and TRI7-fla- mutants

\begin{tabular}{|c|c|c|c|c|c|}
\hline & $\begin{array}{l}\text { Anti-g } \\
\left(g_{8}\right)\end{array}$ & $\begin{array}{l}\text { Anti-g } g_{4}, f \\
\left(g_{4}\right)\end{array}$ & $\begin{array}{l}\text { Anti-g } \\
\left(g_{5}\right)\end{array}$ & $\begin{array}{l}\text { Anti-m } \\
\text { (m) }\end{array}$ & $\underset{(t)}{\text { Anti-t }}$ \\
\hline $\begin{array}{l}\text { TR6 } \\
\text { TR I7 } \\
\text { sJ1748 (Rec.-type V) }\end{array}$ & $\left\{\begin{array}{r}7 \\
<0 \\
<0\end{array}\right.$ & $\begin{array}{r}<0 \\
6 \\
<0\end{array}$ & $\begin{array}{r}<0 \\
8 \\
7\end{array}$ & $\begin{array}{r}<0 \\
9 \\
9\end{array}$ & $\begin{array}{r}13 \\
<0 \\
13\end{array}$ \\
\hline
\end{tabular}

(c) 'Antigen type recombinants' between TRI6- and TRI7-fla' mutants

\begin{tabular}{|c|c|c|c|c|c|c|c|}
\hline & $\begin{array}{l}\text { Anti-g }-g_{1}, g_{5}, p \\
\left(g_{1}\right)\end{array}$ & $\begin{array}{l}\text { Anti-g, } \\
\mathbf{g}_{2}, t\left(g_{1}\right)\end{array}$ & $\begin{array}{l}\text { Anti-g } g_{2}, t \\
\left(g_{2}\right)\end{array}$ & $\begin{array}{c}\text { Anti-g } g_{3}, t \\
\left(g_{3}\right)\end{array}$ & $\begin{array}{c}\text { Anti-g } g_{5}, p \\
\left(g_{5}\right)\end{array}$ & $\begin{array}{l}\text { Anti-f } \\
\text { (f) }\end{array}$ & $\begin{array}{l}\text { Anti-m } \\
\text { (m) }\end{array}$ \\
\hline $\left.\begin{array}{l}\text { TRI6 } \\
\text { TRI7 }\end{array}\right\}$ (Parental type) & $\left\{\begin{array}{r}<0 \\
\mathrm{nt}\end{array}\right.$ & $\begin{array}{r}<0 \\
n t\end{array}$ & $\begin{array}{r}<0 \\
10\end{array}$ & $\begin{array}{r}10 \\
<0\end{array}$ & $\begin{array}{r}<0 \\
8\end{array}$ & $\begin{array}{r}10 \\
<0\end{array}$ & $\begin{array}{r}<0 \\
10\end{array}$ \\
\hline sJI749 (Rec.-type VI) & 4 & nt & 10 & 9 & $<0$ & 9 & $<0$ \\
\hline sJi 756 (Rec.-type VII) & 5 & nt & 10 & IO & $<0$ & 9 & $<0$ \\
\hline sJI76I (Rec.-type VIII) & $<0$ & nt & 9 & IO & $<0$ & 10 & $<0$ \\
\hline sJ1762 (Rec.-type IX) & nt & $<0$ & $<0$ & $<0$ & 8 & $<0$ & I0 \\
\hline sJi764 (Rec.-type X) & nt & $<0$ & $<0$ & $<0$ & 8 & $<0$ & 10 \\
\hline SJ1765 (Rec.-type XI) & nt & 5 & $<0$ & $<0$ & 8 & $<0$ & Io \\
\hline
\end{tabular}

Tryptic peptide maps of flagellins of 'antigen recombinants' and parental-type strains

To show that the 'antigen recombinants' had resulted from recombination within $H I$, flagellins were isolated from the parental strains and from one strain of each of the eleven types of 'antigen recombinants', and their tryptic digests analysed by the finger-printing technique. 
(a) TR6

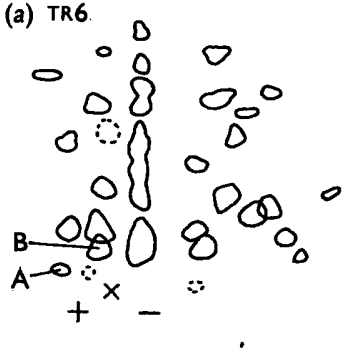

(b) TR16

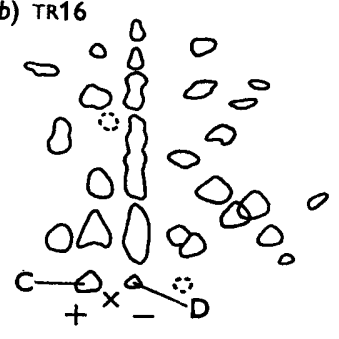

(c) TR17

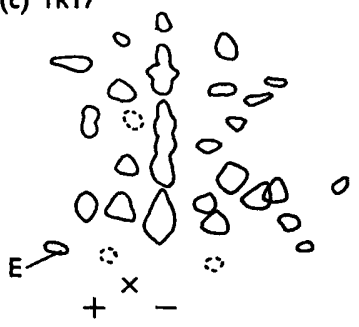

(d) Ss 1740

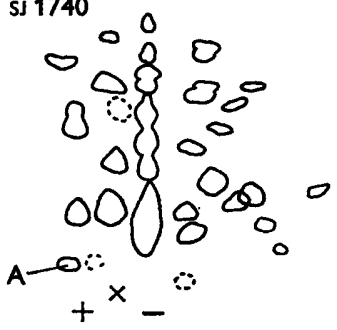

(e) sJ 1744

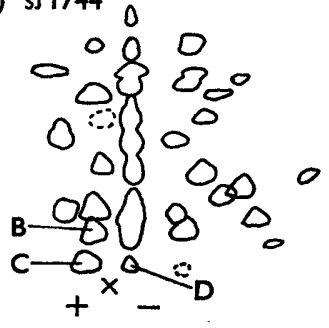

Fig. I. Tracing of the tryptic peptide maps of flagellins of TR6, TR16 and TR 17, gn-complex antigenic derivatives of a phase-I stable strain of Salmonella abortusequi, and SJ1740 and sJi 744, 'antigen recombinants' between TR6 and TRI6. Electrophoresis at pH 6.7 followed by twice of ascending chromatography with $N$-butanol + acetic acid + water $(3+\mathrm{I}+\mathrm{I})$.

\section{Table 8. Log titres (to base 2) of antisera against 'recombinant antigens' after} every absorption with their parental type antigens

Antiserum was absorbed with the mixture of $0.5 \mathrm{~g}$ (in wet weight) of each absorbing strains per $1.0 \mathrm{ml}$. serum at one time. Organisms lysogenized with $\mathbf{P}_{22}$ phage were used for absorption. After every absorption, the remaining activity was tested on the homologous antigens by tube agglutination and expressed as $\log$ titre to base 2 .

Serum

Anti-SJ 740 (Rec.-type I)

Anti-sJi 743 (Rec.-type II)

Anti-sJi 744 (Rec.-type III)

Anti-sJ1747 (Rec.-type IV)

Anti-sJ1748 (Rec.-type V)

Anti-sI 749 (Rec.-type VI)

Anti-sI 756 (Rec.-type VII)

Anti-sJi76I (Rec.-type VIII)

Anti-sJ 762 (Rec.-type IX)

Anti-sJi764 (Rec.-type X)

Anti-sJI 765 (Rec.-type XI)
Absorbed with

TR6 and TRI6

TR6 and TRI6

TR6 and TRI6

TR6 and TRI6

TR6 and TRI7

TRI 6 and TRI 7

TRI 6 and TRI7

TRI 6 and TRI7

TRI 6 and TRI 7

TRI 6 and TRI 7

TRI6 and TRI7
Time of absorption

\begin{tabular}{rrrrr}
\hline 0 & I & 2 & 3 & 4 \\
15 & 8 & 4 & 3 & 3 \\
14 & 4 & I & $<0$ &. \\
14 & 4 & I & $<0$ &. \\
I5 & 9 & 5 & 4 & 4 \\
14 & 5 & I & $<0$ &. \\
15 & 7 & 3 & 2 & 2 \\
14 & 7 & 1 & $<0$ &. \\
15 & 7 & 1 & $<0$ &. \\
14 & 5 & 1 & $<0$ &. \\
15 & 6 & 1 & $<0$ &. \\
15 & 6 & 1 & $<0$ &.
\end{tabular}

Tryptic peptide maps of flagellins of the three parental type strains and two of the 'antigen recombinants' are shown in Fig. I. The approximate number of spots was 35 to 36 for every specimen and almost all the spots, except a few, seemed to be common to all parental and recombinant-type strains. Five spots in all were distinguishable among the maps of the parental-type strains: two spots (A, B in Fig. I) were specific for TR6, two (C, D) for TRI6, and one (E) for TRI7. These different spots 
were found in various combinations on the maps of the 'antigen recombinants', and no other spot except those found on the maps of the parental-type strains was detected. For example, three spots were found besides the common spots on the map of sJi744, a recombinant of TR6 and TRI6: one was the same as B specific for TR6 and the other two were the same as C and D specific for TRI6, respectively. This proves that flagellin of SJI 744 was a mosaic, made up of parts of the flagellins of TR6 and TRI6. The distribution of the spots A-E among the maps of the 'antigen recombinants' is shown in Table 9. It must be kept in mind that there must have been other different peptides which were indistinguishable in the finger-printing maps of the present experiment.

Table 9. Distribution of the differing spots on the peptide maps of flagellins of the 'antigen recombinants'

\begin{tabular}{|c|c|c|c|c|c|c|c|}
\hline \multirow{2}{*}{$\begin{array}{l}\text { Recombinant } \\
\text { between } f a^{-} \\
\text {mutants of }\end{array}$} & \multirow[b]{2}{*}{ Strain } & & \multicolumn{5}{|c|}{ Differing spots* } \\
\hline & & & $\mathbf{A}$ & B & C & D & E \\
\hline & \multirow{2}{*}{ (Parental type) } & $\left\{\begin{array}{l}\text { TR6 } \\
\text { TRI6 }\end{array}\right.$ & + & + & $\dot{+}$ & + & . \\
\hline & & TRI7 & . & . & . & . & + \\
\hline \multirow[t]{4}{*}{ TR6 and TRI6 } & & SJI 740 & + & . & . & . & . \\
\hline & & SJI 743 & + & + & . & . & . \\
\hline & & SJI 744 & . & + & + & + & . \\
\hline & & SJI 747 & . & . & + & + & . \\
\hline TR6 and TRI7 & & SJ1 748 & + & + & . & . & . \\
\hline \multirow[t]{6}{*}{ TRI6 and TRI7 } & & SJI 749 & . & . & $\cdot$ & & + \\
\hline & & SJI 756 & . & . & + & + & . \\
\hline & & $\operatorname{sJI} 761$ & . & . & + & + & . \\
\hline & & SJI 762 & . & . & . & . & + \\
\hline & & SJI 764 & . & . & . & . & + \\
\hline & & SJ1765 & . & . & . & . & + \\
\hline
\end{tabular}

* As for the differing spots A to E, refer to Fig. I.

\section{Mapping of antigenic specificity-determining sections and sections corresponding} to some tryptic peptides of flagellins within $\mathrm{Hr}$

Provided that every 'antigen recombinant' resulted from a single cross-over within $H I$, their origins were inferred from their antigenic factor compositions (Table 6) and their tryptic peptide compositions (Table 9). The results are illustrated in Fig. 2 where $f l a A$ and $f l a L$ are placed on the left and right of $H I$, respectively. The italicized symbols $g_{1}, g_{2}, A$, etc. in the figure represent sections corresponding to the respective factors or peptides. From these inferred origins, an attempt was made to map antigenic specificity-determining sections and sections for the differing peptides within $H r$.

First, the 'antigen recombinants' between the $f l a$ - mutants of TR6 and TR I 6 illustrated in Fig. $2(a)$ will be considered. In SJI747, $g_{2}$ is on the left and separated by the presumed cross-over point from the other sections $g_{1}, g_{4}, f, t, A, B, C$ and $D$. In SJI743, not only $g_{2}$ but also $g_{1}$ is separated from the other sections. Furthermore, $g_{2}, g_{1}$ and $B$, and $g_{2}, g_{1}, B$, and $g_{4}$ are separated from the other groups in sJI 744 and SJI 740, respectively. These suggest the following arrangement of the sections.

$$
-f l a A-\overbrace{g_{2}-g_{1}-B-g_{4}-(f, t, A, C, D)}^{H I}-f l a L-
$$




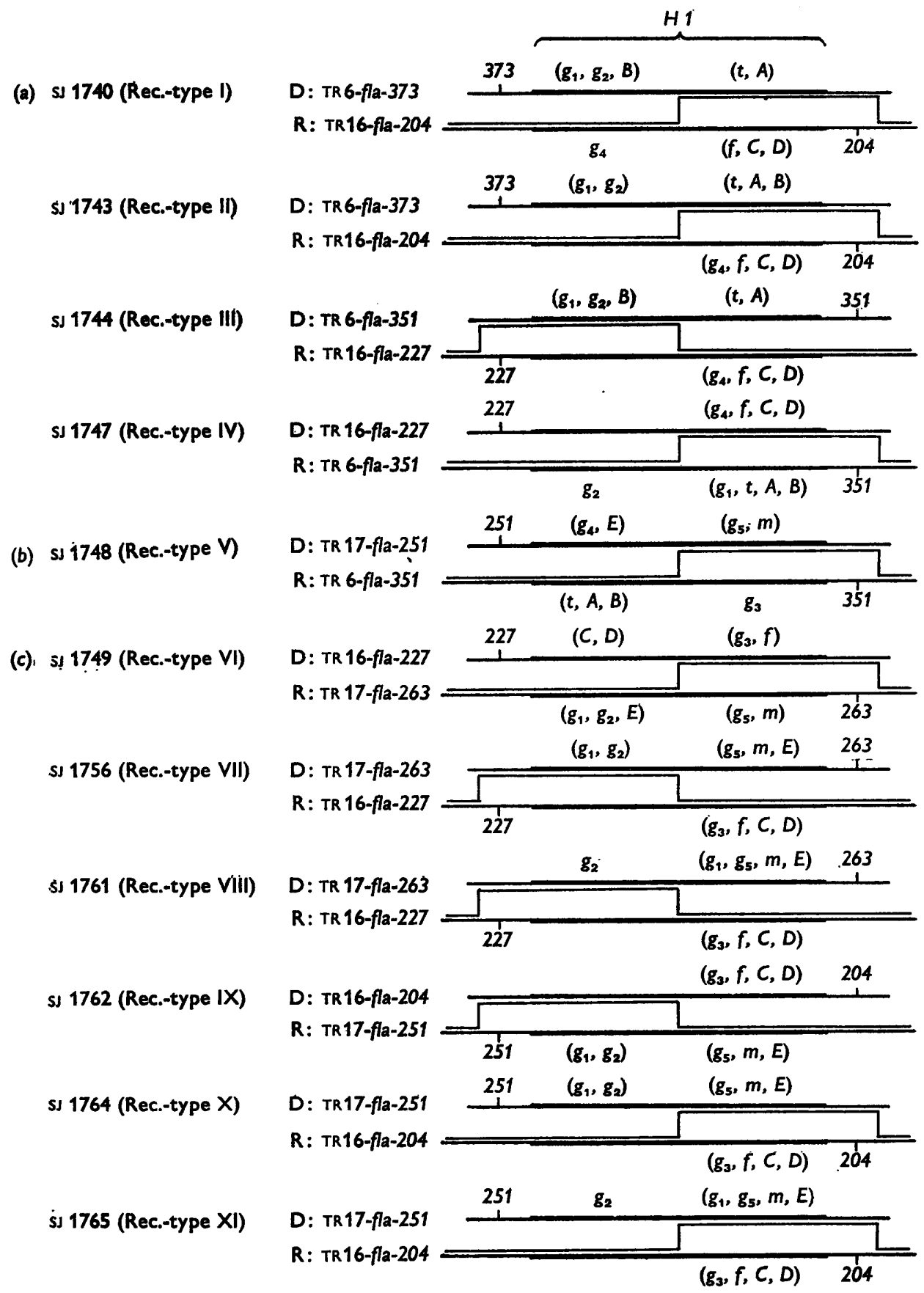

Fig. 2. Inferred origines of the 'antigen recombinants' through a single intra-HI recombination in $\mathbf{P}_{22}$ phage-mediated transduction. (a) Recombinants between $\mathrm{fla}^{-}$mutants of TR6 and TRI6; $(b)$ between those of TR6 and TRI7, and $(c)$ between those of TRI 6 and TRI7. $\mathrm{D}$, donor; $\mathrm{R}$, recipient. $g_{1}, g_{2}$, etc., antigenic specificity-determining sections. $A, B$, etc., sections in $H I$ for the peptides A to $\mathrm{E}$ of the tryptic digests of flagellins (refer to Fig. I). 
Furthermore, sJ 748 (Fig. 2b), the only one 'antigen recombinant' obtained between $f a-$ mutants of TR6 and TRI 7 , suggests the arrangement

$$
-f l a A-(\overbrace{\left.g_{4}, t, A, B, E\right)-\left(g_{3}, g_{5}, m\right.}^{H I})-f l a L-
$$

In SJI76I and sJi765, the 'antigen recombinants' between $f a^{-}$mutants of TRI6 and TRI7 (Fig. $2 c$ ), $g_{2}$ is on the left separated from the other sections $g_{1}, g_{3}, g_{5}, f, m, C, D$, and $E$; and in SII7I5, SII 762 and SJI764, $g_{2}$ and $g_{1}$ are separated from others to the left. In sur 749, $g_{2}, g_{1}, C, D$, and $E$ are separated to the left. Thus, the following order is obtained:

$$
-f l a A-\overbrace{g_{2}-g_{1}-(C, D, E)-\left(g_{3}, g_{5}, f, m\right)}^{H I}-f l a L-
$$

On considering the results as a whole the order is that shown in Fig. 3. No contradiction has been found for any of the 'antigen recombinants' considered.

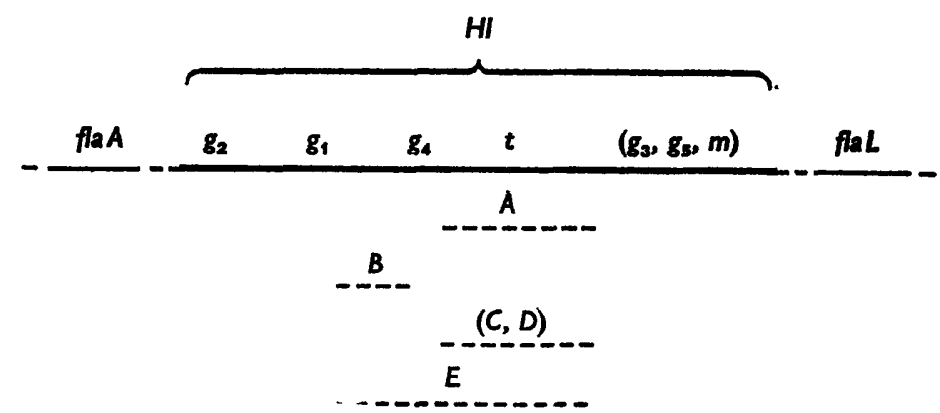

Fig. 3. Arrangement of the antigenic specificity-determining sections and locations of the sections for some tryptic peptides of flagellins within $H r$. Section $f$ is somewhere to the right of $g_{4}, C, D$, and $E$. The orders of the sections in parentheses are not yet determined. $A, B, C$, $D$, and $E$ are somewhere on the respective regions shown by dotted lines.

An attempt to assign antigenic specificities to the specific peptides

It is to be expected that a section specifying a tryptic peptide covering the whole or a part of an antigenic determinant of flagellin will behave in intra- $H I$ recombination always in company with the antigenic specificity-determining section corresponding to that determinant. From this point of view, the sections $A$ to $E$ were examined for their association with any one of the antigenic specificity-determining sections by checking the data presented in Fig. 2. The section $A$ was always associated with section $t$ so far as the present study shows. The other sections $B, C, D$, and $E$ were not associated with any one of the antigenic specificity-determining sections considered here.

\section{DISCUSSION}

Salmonella mutants with altered flagellar antigens may arise through mutation in the $H$ gene (Iino \& Mitani, 1964; Joys \& Stocker, 1966; Yamaguchi \& Iino, 1966). On occasion the serological character of some flagellar antigens is also modified by a gene, $n m l$ (Dr B. A. D. Stocker, personal communication), whose product, probably 
an enzyme, is thought to methylate some lysine residues of flagellin to $\epsilon-N$-methyllysine (NML) residues (Stocker, McDonough \& Ambler, 196I; Kerridge, 1966). We must therefore consider the possibility of mutation in either $\mathrm{Hr}$ or $\mathrm{nml}$ as well as of recombination within $\mathrm{HI}$ as the origin of the 'antigen recombinants' described here. Against this is the behaviour of mutants with altered flagellar antigens selected by cultivation of cells in semi-solid medium containing anti-flagellar antiserum. In this way, we isolated sixteen antigen type mutants from a gn-complex antigenic strain (Yamaguchi \& Iino, 1966). The frequency of their occurrence was $10^{-6}$ to $10^{-7} /$ inoculated organism. In each case, a factor or several factors had been only slightly altered, so retaining cross-reactivity with the original factor or factors. A mutant that had lost one or more factors and/or had gained one or more rather strong ones, such as the 'antigen recombinants', was not found. The possibility may therefore be excluded that the 'antigen recombinants' occurring here at the high frequency of $2 \times 10^{-2}$ ( 26 clones/ I366 $\mathrm{fla}^{+}$transductants) had arisen through mutation.

On the assumption that each 'antigen recombinant' arose by a single cross-over within $H r$, mapping within $H r$ was performed. All the serological data and the results of finger-printing so far obtained are consistent with this assumption, indicating that each of the antigenic specificity-determining sections locates as a unit and that as a whole they are arranged linearly within $H I$.

The present study was made possible by the following facts: (I) $\mathrm{fla}^{-}$mutants whose mutations are closely linked to $H I$ and at either side of it were obtained; (2) as the result of further analysis of the factor compositions of the antigens used, many kinds of anti-factor(s) sera became available; (3) antigenic factors on the 'recombinant antigens' retained almost the same serological character as that of the corresponding factors on the parental type antigens.

In the Kauffmann-White scheme (Kauffman, 1964), nine factors of the gn-complex antigens were described: $f, g, m, p, q, s, t, u$, and $z_{51}$. In the present study, it has been shown that the factor $g$ is a complex composed of two or more of at least 5 factors, $g_{1}$ to $g_{5}$. It must be mentioned here that, if these gn-complex antigens are modified by the presence or absence of $\epsilon-N$-methyllysine (NML), namely $n m l^{+}$or $n m l^{-}$, the analysis of the gn-complex antigens without NML may give somewhat differing results from the present one.

The presence of chromosomal sections marked with the respective antigenic specificities of flagellin within $H I$ has been shown in the present study, but this does not necessarily mean that the specificity of an antigenic determinant of flagellin depends exclusively on the amino acid sequence or the primary structure specified by the corresponding section. It has been reported that ribonuclease oxidized by performic acid, a process which markedly alters its conformation without any change in its primary structure, does not cross-react serologically with native ribonuclease (Brown, 1962). It has also been reported that in Salmonella, several antigenic factors present on the wild-type flagellin may change simultaneously as a result of only one presumptive amino acid replacement (Joys \& Stocker, 1966; Yamaguchi \& Iino, I966). Therefore, the amino acid sequence determined by an antigenic specificity-determining section manifests the specific antigenicity only when it has a specific tertiary structure in the whole conformation of the flagellin molecule.

Although some new specificities with weak antigenicity were detected on several 'recombinant antigens', all the 'recombinant antigens' obtained here are almost 
perfect mosaics of the parental antigens in their serological nature. This implies that the tertiary structure of individual antigenic determinants on the recombinant flagellins had suffered little or no change by recombination. This may also be expected from the strong resemblance between the tryptic peptide maps of the parental flagellins. Experiments to obtain 'recombinant antigens' between the non-cross-reacting antigens a and gn-complex were carried out in parallel with the present study, but were unsuccessful. One of the reasons may be that since a and gn-complex flagellins differ considerably in their amino acid composition (McDonough, 1965), recombinant flagellins, if produced, might be so abnormal in their conformation that they could not form motile flagella.

In globular proteins like flagellin, the folding of the polypeptide chains brings into apposition amino acids remote from each other in the primary structure. Some antigenic determinants may therefore include amino acids from two or more points along the chain. For such a determinant, the antigenic specificity-determining section should locate as two or more units within the structural gene. Although it was shown that each of the antigenic specificity-determining sections considered in the present study is located as a unit within $H I$, this does not exclude the above possibility.

Many attempts have been made to define the structural features of antigenic determinants of globular proteins by isolating and characterizing fragments of the whole molecule which retain the ability to combine with specific antiserum. In the present study, an attempt was made to assign antigenic specificities of flagellin to some specific tryptic peptides, on the assumption that the tryptic peptide corresponding to an antigenic determinant on the flagellin molecule always corresponds to the antigenic specificity manifested by the determinant in intra- $H r$ recombination. Though the data are as yet insufficient for complete assignment, the present results are sufficient to suggest that more peptide analysis will make this approach possible.

Contribution from the National Institute of Genetics, Japan, No. 693.

This work was supported by a grant from the Research Fund of the Ministry of Education of Japan. This paper forms part of the doctoral thesis (1967) of S. Yamaguchi approved by Tokyo Kyoiku University, Tokyo, Japan. The authors wish to thank Dr D. Kerridge (Sub-Department of Chemical Microbiology, Department of Biochemistry, Tennis Court Road, Cambridge) for a gift of $\epsilon-N$-methyllysine.

\section{REFERENCES}

Adams, M. H. (1959). Bacteriophages. New York: Interscience Publishers, Inc.

ANDREWS, F. W. (1922). Studies in group-agglutination. I. The Salmonella group and its antigenic structure. J. Path. Bact. 25, 515.

AsakuRA, S., EgUCH, G. \& InNo, T. (1964). The reconstitution of bacterial flagella in vitro. J. molec. Biol. I0, 42.

BROWN, R. K. (1962). Studies on the antigenic structure of ribonuclease. III. Inhibition by peptides of antibody to performic acid-oxidized ribonuclease. J. biol. Chem. 237, I 62.

EDWARDs, P. R. \& BrunER, D. W. (1942). Serological identification of Salmonella cultures. Circ.Ky agric. Exp. Stn, no. 54.

EDWARDS, P. R. \& EwING, W. H. (1955). Identification of Enterobacteriaceae. Minneapolis, Minn., U.S.A.: Burgess Publ. Co.

ENomoto, M. \& Ino, T. (1962). Chromatography and electrophoresis of flagellin of Salmonella abortusequi. Rep. natn. Inst. Genet., Misima, 13, 76. 
InNo, T. (1959). Subunits of $H l$ gene in Salmonella. Rept. natn. Inst. Genet., Misima ro, 11 I .

IrNo, T. (1960). Transduction between curly flagellar mutants in Salmonella. Rep. natn. Inst. Genet., Misima, II, 73

InNo, T. \& ENomoto, M. (1966). Genetical studies of non-flagellate mutants of Salmonella. J. gen. Microbiol. 43, 315.

InNo, T. \& LeDERBERG, J. (1964). Genetics of Salmonella. In The World Problem of Salmonellosis, p. III. The Hague: Dr W. Junk-Publishers.

InNo, T. \& MrTAN, M. (1964). Mutation of flagellar antigen-I 22 in Salmonella. Rep. natn. Inst. Genet., Misima $15,98$.

JoYs, T. M. \& STOCKeR, B. A.D. (1963). Mutation and recombination of flagellar antigen $i$ of Salmonella typhimurium. Nature, Lond. 197, 413.

Joys, T. M. \& STOCKER, B. A. D. (I965). Complementation of non-flagellate Salmonella mutants. J. gen. Microbiol. 4I, 47.

JoYs, T. M. \& STOCKER, B. A. D. (1966). Isolation and serological analysis of mutant forms of flagellar antigen $i$ of Salmonella typhimurium. J. gen. Microbiol. 44, 121.

Kaufrmann, F. (1964). Das Kauffimann-White Schema. In The World Problem of Salmonellosis, p. 21. The Hague: Dr. W. Junk-Publishers.

KERRIDGE, D. (1966). Flagellar synthesis in Salmonella typhimurium: factors affecting the formation of the flagellar $\epsilon-N$-methyllysine. J. gen. Microbiol. 42, 71.

Kerridge, D., Horne, R. W. \& Glauert, A. M. (1962). Structural components of flagella from Salmonella typhimurium. J. molec. Biol. 4, 227.

LeDERBERG, J. \& EDWARDS, P. R. (1953). Serotypic recombination in Salmonella. J. Immun. 7x, 232.

MCDonough, M. W. (1965). Amino acid composition of antigenically distinct Salmonella flagellar proteins. J. molec. Biol. I2, 342.

MeYNeLl, E. W. (196I). A phage, $\chi$, which attacks motile bacteria. J. gen. Microbiol. $25,253$.

SASAKI, I. (1962). $x$-phage resistance in Salmonella having g-group antigen. I. Host range mutants of $\chi$-phage. Virus (Japan) 4, 168.

STOCKER, B. A. D., ZINDER, N. D. \& LEDERBERG, J. (1953). Transduction of flagellar characters in Salmonella. J. gen. Microbiol. 9, 410.

Stocker, B. A. D., McDonough, M. W. \& Ambler, R. P. (196I). A gene determining presence or absence of $\epsilon-N$-methyllysine in Salmonella fiagellar protein. Nature, Lond. 189, 556.

YAMAGUCHI, S. (1968). Sensitivity of the $g$-complex antigenic Salmonella strains to M 8, a host-range mutant of bacteriophage $\chi$. J. gen Virol. 2, 187.

YamaGUCh, S. \& IINo, T. (1966). Mutation of $g$-complex antigen in Salmonella. Rep. natn. Inst. Genet., Misima, 16, 94.

ZINDER, N. D. (1957). Lysogenic conversion in Salmonella typhimurium. Science, N.Y. 126, 1237.

ZINDER, N. D. \& LEDERBERG, J. (1952). Genetic exchange in Salmonella. J. Bact. 64, 679. 